Jurnal Olahraga \& Kesehatan Indonesia

Volume 1 Nomor 2 (2021)

E-ISSN: 2747-061X

available online at https://jurnal.stokbinaguna.ac.id/index.php/jok

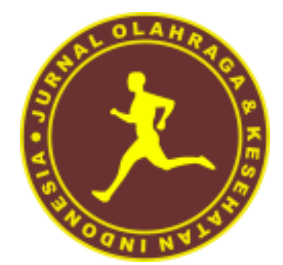

\title{
KONTRIBUSI VARIASI LATIHAN LADDER DRILL TERHADAP KELINCAHAN ATLET BULU TANGKIS
}

\author{
Hardi Fansuri $^{1}$ *, Rahman Situmeang ${ }^{2}$ \\ ${ }^{12}$ Universitas Negeri Medan, Sumatera Utara, Indonesia, 20221 \\ * Coressponding Author: hardifansuri06@gmail.com
}

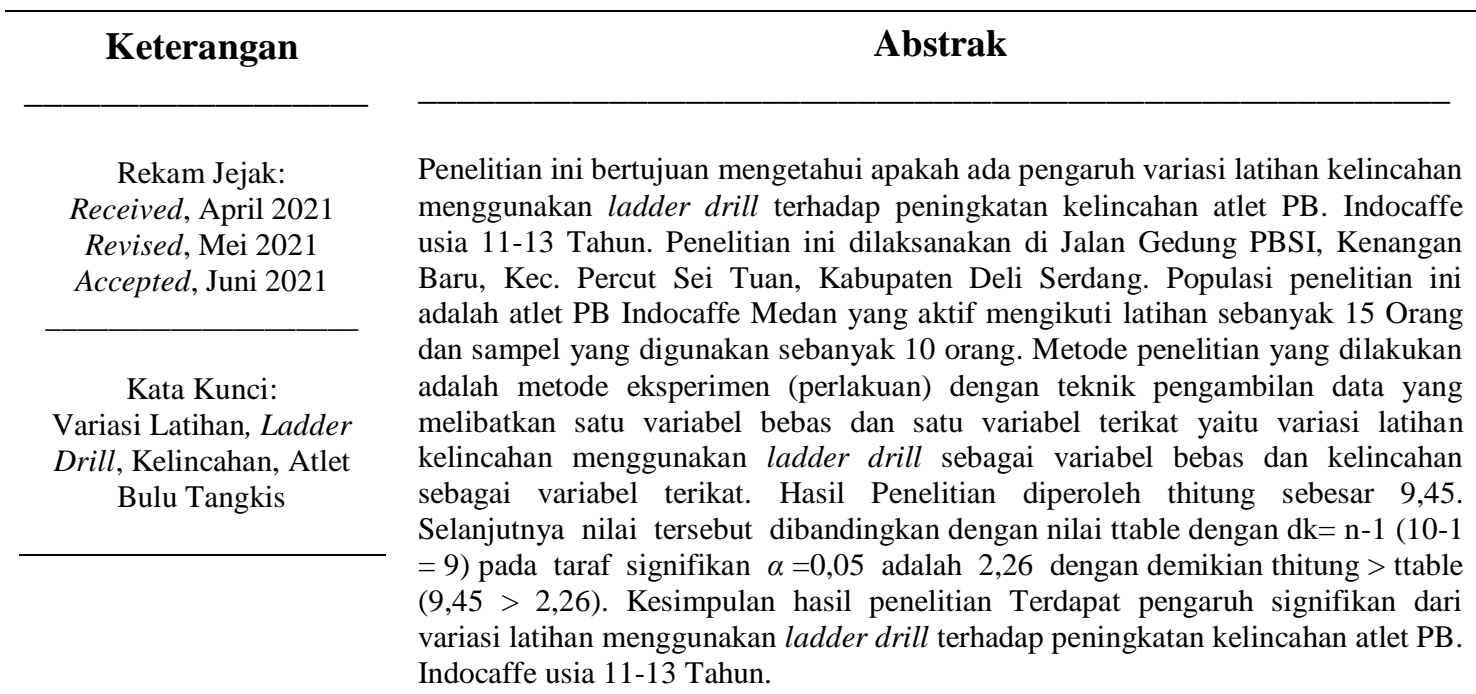

Copyright (C) 2020

Jurnal Olahraga \& Kesehatan Indonesia 


\section{PENDAHULUAN}

Olahraga bulu tangkis di Indonesia telah menempatkan diri sebagai olahraga yang sangat populer di kalangan masyarakat, oleh karena prestasi yang dicapai dan mampu bersaing dengan negara lain di dunia. Hal ini dapat dilihat dengan banyaknya masyarakat yang ikut serta dalam setiap kegiatan olahraga bulutangkis yang diselenggarakan, baik dalam bentuk pertandingan tingkat RT hingga tingkat dunia, seperti Thomas dan Uber Cup atau Olimpiade. Olahraga bulutangkis dapat dimainkan mulai dari anak-anak hingga orang dewasa dan dapat dilakukan di dalam maupun di luar ruangan. Banyak orang melakukan olahraga bulutangkis dengan berbagai macam tujuan, diantaranya untuk rekreasi dan hiburan, menjaga kebugaran dan kesehatan sampai untuk tujuan olahraga prestasi.

Olahraga bulutangkis termasuk olahraga kompetitif yang memerlukan gerakan eksplosif,

banyak gerakan berlari, meloncat untuk smash, refleks, kecepatan merubah arah dan juga membutuhkan koordinasi mata-tangan yang baik. Olahraga bulutangkis sama dengan olahraga permainan yang lain, dimana seseorang untuk dapat bermain harus menguasai terlebih dahulu teknik - teknik dasar permainan yang dipergunakan. Teknik - teknik dasar tersebut mempunyai karakteristik yang sesuai dengan bentuk permainannya. Dalam permainan bulutangkis teknik -

teknik dasar yang utama adalah Smash, Dropshot, Drive, Pukulan Serve, Return Service.

Teknik dasar yang baik pada cabang olahraga bulutangkis maupun olahraga lainnya tidak luput dari mengikuti proses pembinaan dan pelatihan. Pelaksanaan teknik dasar haruslah didukung dengan komponen biomotorik dalam tubuh atlet yang ditingkatkan melalui proses latihan. Latihan merupakan aktivitas olahraga yang sistematis dalam waktu yang lama, ditingkatkan secara progresif dan individual dan mengarah kepada ciri-ciri fungsi fisiologis dan psikologis manusia untuk mencapai sasaran yang telah ditetapkan (Bompa, 1999). Latihan bulutangkis pada dasarnya harus mendahulukan unsur pembinaan fisik, teknik, taktik atau mental yang kokoh untuk dapat menghasilkan prestasi secara optimal. Oleh karena itu, pembinaan harus dilakukan secara sistematis, berjenjang dan berkesinambungan.

Keberadaan klub-klub bulutangkis mempunyai peran yang sangat besar dalam mendukung upaya pencapaian prestasi yang optimal, karena melalui klub-klub inilah bibit-bibit pemain dapat ditemukan kemudian dibina dan dikembangkan. Namun bibit-bibit atlet ini juga tidak akan berkembang tanpa adanya kejuaraan, baik itu kejuaraan di daerah maupun nasional. Dalam suatu pertandingan baik itu kejuaraan daerah atau pun nasional ada banyak atlet yang tidak bisa menampilkan penampilan terbaiknya. Hal ini merupakan suatu permasalahan bagi pelatih yang bersangkutan. Seperti telah diungkapkan di atas untuk mencapai prestasi yang optimal tidak datang dengan sendirinya namun harus melalui proses yang panjang. Proses pembinaan dimulai dengan menemukan bibit- bibit atlet berbakat, kemudian dibina melalui latihan yang teratur, terarah, dan terencana dengan baik serta dengan penguasaan teknik dan taktik yang benar. Sejak dari tahap persiapan sampai dengan proses pembinaan atlet, disamping aspek fisik perlu juga aspek psikologis tidak boleh diabaikan dalam pembinaan atlet.

Dari hasil observasi lapangan pada tanggal

15 September 2019 pada PB. Indocaffe Medan diperoleh hasil kemampuan atlet dari aspek teknik maupun fisik. Teknik pengambilan data awal melalui lembar pengamatan yaitu peneliti mengamati kemampuan atlet PB. Indocaffe Medan dan memberikan penilaian secara objektif dibantu oleh pelatih bulutangkis PB.Indocaffe Medan. Jumlah atlet keseluruhan PB. Indocaffe Medan berjumlah 15 orang usia 11-13 Tahun. Atlet yang menjadi subjeck pengamatan terdiri dari sebagian atlet PB. Indocaffe Medan yaitu sebanyak 6 orang atlet. Hasil lembar observasi yang dilakukan peneliti yang dibantu oleh pelatih diperoleh kemampuan teknik pengembalian service atlet yaitu dapat dilihat pada Lampiran 2.

Pada Lampiran 2 terlihat kemampuan pengembalian memiliki kriteria presentase terendah yaitu 50\%. Selanjutnya pada Lampiran 3 diperoleh kemampuan fisik pada aspek kelincahan memiliki presentase nilai terendah yaitu $36,66 \%$. Dari data di atas peneliti menyimpulkan 
bahwa teknik pengembalian cokc memiliki hubungan dengan kemampuan fisik kelincahan. Jika kelincahan atlet rendah maka teknik pengembalian cokc dapat berpengaruh sehingga berdampak pada kekalahan pada atlet saat bertanding. Untuk itu peneliti menetapkan komponen fisik yaitu kelincahan harus ditingkatkan untuk memaksimalkan kemampuan atlet saat bertanding.

Hasil pengamatan pada sesi latihan atlet peneliti melihat pelatih lebih menekankan bentuk latihan teknik dan penerapan bentuk latihan fisik khususnya latihan kelincahan masih kurang variatif. Pelatih cenderung menerapkan latihan footwork dan tidak melakukan variasi dan kombinasi latihan kepada atlet. Sehingga menyebabkan kurang maksimalnya atlet dalam melakukan latihan dikarenakan tingkat kejenuhan pada atlet. Untuk itu dalam merencanakan bentuk latihan perlu adanya penerapan bentuk latihan yang variatif yang dapat meransang rasa keingintahuan dan motivasi atlet dalam melaksanakan program latihan yang sudah direncanakan.

Hasil temuan pada PB. Indocaffe Medan yaitu tingkat kemampuan biomotorik kelincahan masih rendah dibuktikan hanya $36,66 \%$ atlet yang memiliki kategori baik. Untuk itu perlu adanya peningkatan agar kemampuan fisik kelincahan pada atlet bulutangkis PB. Indocaffe Medan. Kelincahan sangat penting pada atlet bulutangkis untuk mempermudah pengembalian cokc dan membangun serangan yang cepat pada atlet. Atlet cenderung tidak menyukai bentuk latihan fisik dan kelincahan merupakan salah satu komponen biomotorik yang berkontribusi besar dalam pelaksanaan teknik dan pergerakan pada atlet bulutangkis. Untuk itu perlu adanya bentuk latihan kelincahan yang variatif diterapkan kepada atlet bulutangkis agar memotivasi atlet untuk dapat menerapkan bentuk latihan kelincahan.

Banyak bentuk latihan kelincahan yang dapat diterapkan kepada atlet salah satunya latihan ladder drill. Menggunakan ladder drill akan dapat memacu peningkatan kelincahan atlet. Lepas dari ladder dapat meningkatkan kelincahan namun penerapannya harus variatif untuk mengantisipasi kejenuhan dalam menerapkan latihan. Khoiruzzaman Assya'bani (2016:41) Kelincahan dapat dilatih dengan banyak cara untuk meningkatkannya, salah satunya adalah ladder drills / latihan tangga. Ladder merupakan salah satu bentuk alat latihan fisik yang menyerupai anak tangga yang diletakkan pada bidang yang datar atau di lantai.

Dari hasil observasi di atas merupakan kemampuan atlet yang dinilai melalui lembar pengamatan peneliti. Untuk itu peneliti bertujuan untuk mengetahui kelincahan atlet jika diberikan bentuk perlakuan latihan yang bervariatif. Latihan yang direncanakan untuk meningkatkan kelincahan atlet yaitu menerapkan bentuk latihan variasi menggunakan ladder drill untuk meningkatkan kelincahan pada atlet. Untuk itu peneliti menetapkan judul penelitian ini yaitu Pengaruh Variasi Latihan kelincahan menggunakan ladder drill Terhadap Peningkatan Kelincahan Atlet Bulutangkis Usia 11- 13 Tahun PB. Indocaffe Medan Tahun 2020.

\section{METODE}

Metode penelitian ini menggunakan metode kuantitatif, Sugiono (2017:14) metode penelitian kuantitatif dapat diartikan sebagai metode penelitian yang didasarkan pada filsafat positivisme dugunakan untuk meneliti pada populasi dan sampel tertentu, analisis bersifat kuantitatif atau statistik dengan tujuan untuk menguji hipotesis yang telah ditetapkan. Metode penelitian yang digunakan adalah metode eksperimen (perlakuan) dengan teknik pengambilan data yang melibatkan satu variabel bebas dan satu variabel terikat yaitu variasi latihan kelincahan menggunakan ladder drill sebagai variabel bebas dan kelincahan sebagai variabel terikat.

Sebelum diberi perlakuan, dilakukan tes awal kelincahan pada atlet (pre-test). Kemudian semua sampel diberi perlakuan yang sama dalam melakukan variasi latihan kelincahan menggunakan ladder drill kepada atet. Perlakuan ini diberikan selama 18 kali pertemuan, (6 minggu dengan volume latihan 3 kali seminggu), selanjutnya dilakukan tes akhir yaitu tes kelincahan atlet (post-test) yang diperoleh kemudian diolah dengan prosedur statistik dengan menggunakan perhitungan t-hitung, uji normalitas dan uji homogenitas. 
Tabel 1. Desain Penelitian (Randomized Group Pre-Test and Post-Test).

Pre-Test Kelincahan Perlakuan Ladder Drill Post-Test Kelincahan

$\mathrm{T} 1$

$\mathrm{X} 1$

Y1

Sumber. Sudjana (1999)

Dalam desain ini diberikan kepada kelompok tunggal dengan diberikan terlebih dahulu pretest (tes awal) dan setelah diberi treatment sampel diberi posttest (tes akhir). Untuk mengumpulkan data dari sampel penelitian diperlukan alat yang disebut instrument. Instrument penelitian adalah alat untuk mengukur data. Menurut Arikunto (2007:126) menjelaskan bahwa "Instrumen adalah alat pada waktu peneliti menggunakan metode". Berdasarkan pengertian tersebut, untuk memperoleh data hasil penelitian berupa peningkatan kemampuan atlet digunakan instrument penelitian berupa tes kelincahan, yang dilakukan peneliti. Pengumpulan data dalam penelitian ini adalah dengan tes pengukuran. Instrumen tes yang digunakan untuk pengukuran awal (pre-test) maupun pengukuran akhir (post-test) menggunakan side step (Imran Akhmad, 2013).

Tabel 2. Norma Penilaian Kelincahan Side Step Tes

\begin{tabular}{cccccc}
\hline Jenis Kelamin & Baik Sekali & Baik & Cukup & Kurang & $\begin{array}{c}\text { Kurang } \\
\text { Sekali }\end{array}$ \\
Perempuan & $<46$ & $42-45$ & $38-41$ & $34-37$ & $>33$ \\
Laki-Laki & $<50$ & $46-49$ & $42-45$ & $38-41$ & $>37$ \\
\hline
\end{tabular}

Data yang sudah diperoleh dari hasil Pre-test dan post-test di analisis dengan menggunakan perhitungan uji normalitas dan uji homogenitas.

\section{HASIL \& PEMBAHASAN}

Hasil test pengukuran yang dilakukan dilapangan merupakan temuan penelitian selama 6 minggu. Dilakukan untuk mengungkapkan kebenaran hipotesa yang telah diajukan. Hasil tes dan pengukuran yang telah diolah melalui rumus statistik menunjukkan deskripsi data sebagai berikut:

Tabel 3. Hasil data Pre-test dan Post-test Tes

\begin{tabular}{ccc}
\hline Deskripsi Data & \multicolumn{2}{c}{ Kelincahan Atlet } \\
Rentang & $35-46$ & Post-test \\
Nilai Rata-rata & 40,8 & 47,3 \\
Simpangan baku & 3,79 & 3,09 \\
Beda rata-rata & \multicolumn{2}{c}{6,5} \\
Simpangan baku beda & \multicolumn{2}{c}{2,17} \\
t-hitung & \multicolumn{2}{c}{9,45} \\
t-tabel & \multicolumn{2}{c}{2,26} \\
\hline
\end{tabular}

Berdasarkan data pre-test dan post-tes Tes Kelincahan Pada Atlet Bulutangkis Usia 11-13 Tahun PB.Indocaffe Medan Tahun 2020 dapat dideskripsikan data penelitian yaitu pada data pre-test diperoleh rentang kelincahan atlet sebesar 35 data terendah dan 46 data tertinggi. Nilai rata-rata kelincahan atlet diperoleh 40,8 dan simpangan baku data diperoleh 3,79. Selanjutnya pada data post-test Tes Kelincahan Pada Atlet Bulutangkis Usia 11-13 Tahun PB.Indocaffe Medan Tahun 2020 dapat dideskripsikan data penelitian yaitu pada data post- test diperoleh rentang kemampuan power otot lengan atlet sebesar 43 data terendah dan 53 data tertinggi. Nilai rata-rata kelincahan atlet diperoleh 47,3 dan simpangan baku data diperoleh 3,09.

Setelah mendapatkan data baku penelitian yaitu data pre-test dan post test kelincahan atlet maka dilakukannya pengujian hipotesis menggunakan uji-t dependent sehingga diperoleh beda 
rata-rata pre-test dan post-test sebesar 6,5. Data simpangan baku beda sebesar 2,17. Berdasarkan data beda dan simpangan baku beda maka dilakukannya pengujian uji $\mathrm{T}$ dependen untuk melihat pengaruh dari latihan variasi latihan kelincahan terhadap peningkatan Kelincahan Pada Atlet Bulutangkis Usia 11-13 Tahun PB.Indocaffe Medan Tahun 2020 dan diperoleh T-hitung sebesar 9,45. Untuk mengetahui pengaruh antar variabel maka dibandingkan dengan T-tabel sebesar 2,26. Hasil hipotesis pada penelitian ini t-hit > t-tab dengan demikian Ho ditolak Ha diterima.

Tabel 4. Uji Normalitas Data Kelincahan

\begin{tabular}{cccccccc}
\hline Normalitas & Sampel & $\begin{array}{c}\text { Simpangan } \\
\text { Baku }\end{array}$ & Varians & Rata- Rata & L-Hit & L-Tab & $\begin{array}{c}\text { Kesimpulan } \\
\text { Lo }<\text { Lt }(0,05),\end{array}$ \\
Pre-Test & 10 & 3,79 & 14,4 & 40,8 & 0,1 & 0,25 & $\begin{array}{c}\text { Kaka data berdistribusi } \\
\text { Normal } \\
\text { maks }\end{array}$ \\
Post-Test & 10 & 3,09 & 9,56 & 47,3 & 0,2 & 0,25 & $\begin{array}{c}\text { Lo }<\text { Lt }(0,05), \\
\text { maka data berdistribusi } \\
\text { Normal }\end{array}$ \\
\hline
\end{tabular}

Berdasarkan tabel diatas pada data pre-test data sampel berjumlah 10, simpangan baku data pretest sebesar 3,79, variasn data pre-test sebesar 14,4, rata- rata data pre-test sebesar 40,8. Berdasarkan data diatas dilakukan uji prasyarat data penelitian dan diperoleh L-hitung sebesar 0,197 dan dibandingkan dengan L-Tabel sebesar 0,258 dengan demikian L-Hit < L-Tabel maka Ho ditolak Ha diterima. Dapat disimpulkan bahwa data hasil tes kelincahan Atlet Bulutangkis Usia 11-13 Tahun PB.Indocaffe Medan berdistribusi "Normal".

Selanjutnya pada Uji Normalitas data post-test kelincahan atlet dengan sampel 10, simpangan baku data post-test sebesar 3,09, variasn data post-test sebesar 9,59, rata-rata data post-test sebesar 47,3. Berdasarkan data diatas dilakukan uji prasyarat data penelitian dan diperoleh L-hitung sebesar 0,238 dan dibandingkan dengan L-Tabel sebesar 0,241 dengan demikian L-Hit < L-Tabel maka Ho ditolak Ha diterima. Dapat disimpulkan bahwa data posttest data hasil tes kelincahan Atlet Bulutangkis Usia 11-13 Tahun PB.Indocaffe Medan berdistribusi "Normal".

\section{SIMPULAN}

Berdasarkan hasil penelitian di atas, maka dapat ditarik kesimpulan pada penelitian ini yaitu terdapat pengaruh signifikan dari variasi latihan menggunakan ladder drill terhadap peningkatan kelincahan atlet PB. Indocaffe usia 11-13 Tahun. Adapun kesimpulan dalam penelitian ini yaitu hasil penelitian ini membuktikan bahwa variasi latihan kelincahan menggunakan ladder drill dapat meningkatkan kelincahan atlet bulutangkis PB. Indocaffe Medan.

\section{DAFTAR PUSTAKA}

Bompa, Tudor. (2009). Theory and Methodology of Training. Iowa: Kendall/Hunt Publishing Company.

Brown, L.E. \& Ferrigno, V.A. (2005). Training for Seed, Agility, and Quickness. New York: Human Kinetics.

Grice, Tony. (2007). Bulutangkis. Jakarta: PT Raja Grafindo Persada.

Harsono. (1988). Coaching dan Aspek-Aspek Psikologis dalam Coaching. Tambak Kusuma. James, Poole. (2008). Belajar Bulutangkis. Bandung: Pionir Jaya.

Kunta, Purnama Sapta. (2010). Kepelatihan Bulutangkis Modern. Surakarta: Yuman pustaka Nurhasan. (2001). Tes Pengukuran Dalam Pendidikan Jasmani, Prinsip-prinsip dan Penerapannya. Jakarta: Depdiknas. 
Hardi Fansuri - Rahman Situmeang

hardifansuri06@gmail.com

Sajoto. (1988). Pembinaan Kondisi Fisik dalam Olahraga. Jakarta: Depdikbud.

Salim, Agus. (2008). Buku Pintar Bulutangkis. Jakarta: PT Intimedia.

Subardjah, Herman. (2000). BuluTangkis. Solo: CV Setia Aji Surakarta.

Sugiyono. (2007). Statistika Untuk Penelitian. Bandung: Alfabeta.

Suharsimi, Arikunto. (2006). Prosedur Penelitian Suatu Pendekatan Praktik. Jakarta: Rineka Cipta.

Syahri, Alhusni, M.S. (2007). Gemar Bermain Bulutangkis. Jakarta: Direktorat Jendral Pendidikan Dasar dan Menengah. 